\title{
Anti-terror study tracks gas dispersal
}

Plumes of inert gas are rising above Manhattan this week as part of a research programme to improve the US response to terrorist attacks. Researchers will track the fate of seven different gases to test and refine models of how chemical, biological or radioactive material might spread through the city.

Emergency services responding to attacks in built-up areas already have to balance helping the injured, evacuating survivors and sealing the site for forensic examination. But responding to an explosive release of harmful airborne material would be even more difficult. To decide how far to move people from the scene and in which direction, authorities need some idea of how material will spread, and how that is affected by factors such as the weather.

Data from the New York experiments, principally funded by the Department of Homeland Security (DHS), will be fed into computer models that can be run in an emergency, to predict how a plume of material will disperse over the following hours and to inform emergency services about how to respond.

It is impossible to test every material, in every location and in all conditions. But Tom Keiss, acting programme manager for radio-

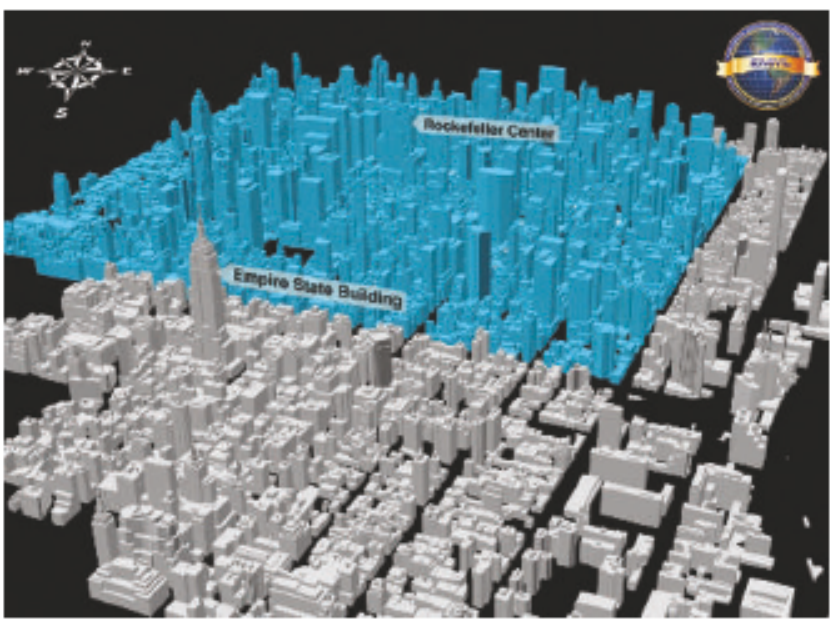

Researchers willmonitor the movement of test gases across New York.

on six days (see graphic), determined by the weather, between 6 and 26 August. Using nearly 180 samplers and 35 weather stations, researchers from government and university labs will track the gases' movement through the streets and into buildings and the subway system.

The research is part of the fouryear Urban Dispersion Programme, which began in 2003. Earlier tracer experiments took place in Oklahoma City and Salt Lake City, and a small-scale preliminary to the Manhattan experiments was carried out around Madison Square Garden in March.

Across the Atlantic, the British government is interested in tracer

logical countermeasures in the DHS Office of Research and Development, says the results from such experiments could lead to models accurate enough for use in an emergency.

${ }^{\alpha}$ These models could tell us what sort of area first-responders should evacuate, and even the information you would give the public," he says, such as safe routes out of a city. ${ }^{\circ} \mathrm{We}$ consider this to be a sound investment that can save lives."

The gases are being released from an area of two square kilometres south of Central Park releases in London. It tested its models with data from a tracer experiment to examine air pollution in the city, and is deciding whether to fund a large-scale tracer-release programme in London.

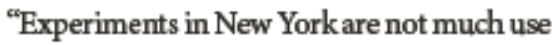
toLondon or Paris. Our cities are very different physically, and have different climates," says Alan Robins, a specialist in environmental fluid mechanics at the University of Surrey, Guildford, and chair of the London project.

Tom Simonite

\section{Japan accelerates global supercomputer war}

TOKYO

Japanese groups are competing to reclaim for their country the honour of owning the world's fastest supercomputer.

Japan lost the title last autumn, when IBM's BlueGene/L computer — which has a maximum speed of 140 million million calculations per second (140 teraflops) overtook the Yokohama-based Earth Simulator (see Nature 431, 618; 2004).

Last month, a group that indudes Toshiba, the University of Tokyo and the Institute of Physical and Chemical Research announced plans for a computer that would be 73 times faster - capable of 10,000 million million calculations per second (10 petaflops). It said that the project could cost between $¥ 80$ billion (US $\$ 700$ million)and $¥ 100$ billion, and would be ready by March 2011.

But experts are already expressing doubts. Tetsuya Sato, director of the Earth
Simulator, says the project will be held back by the limits on semiconductor technology, which is reaching the narrowest dimensions of circuits that can be etched. "I am very sceptical," he says.

Erich Strohmaier, a computer scientist at Lawrence Berkeley National Laboratory, says difficulties with increased heat output and power consumption would also hamper the development of faster processors. But he predicts that technological advances could produce a machine of at least 3 petaflops by 2011, and doesn't rule out the Japanese team reaching their goal. "It's an ambitious project," he says. "With an exceptional system design, 10 petaflops seems within reach."

Meanwhile, Sato has his own plan hooking the 40-teraflop Earth Simulator to a new 400-teraflop computer. The smaller machine would act as a 'macro-structure', performing large-scale calculations and directing the more intricate operations of the larger one, he told Nature.

Sato thinks that changing the networks' wiring in this way would allow the equivalent of 16 petaflops. "We are close to the technological limit," he says. "But this solution is based on physics, not technology." Strohmaier warns, however, that such hierarchical structures are a risk because they sacrifice a great asset of the Earth Simulator - " a tried and tested technology, which we understand and know how to program," he explains.

This computing power, if achieved, could be used to model climate change, drug metabolism and galaxy formation, for example. But it would be very expensive. It is not dear which of the projects, if either, will make it into the Japanese science ministry's budget requests, due this month.

David Cyranoski 